\title{
New Technologies for Value Added Products from Coconut Residue
}

\author{
Navin K. Rastogi \\ Department of Food Engineering, CSIR-Central Food Technological Research Institute (CFTRI), \\ Mysore 570 020, India \\ nkrastogi@cftri.res.in
}

Keywords: coconut palm, wet processing, by-products utilization

\begin{abstract}
This paper deals with the technologies developed in the field of coconut research at CFTRI in the last three decades including process for desiccated coconut, technology development for the production of spray dried coconut milk powder, wet processing of coconut, vinegar generation from coconut water, virgin coconut oil, tender coconut based beverage, coconut spread etc. CFTRI is in forefront in developing technologies for coconut-based products. Some of these technologies have been successfully transferred and most of the produce is being exported. Our current research efforts are focused on production of low fat dietary fiber from coconut residue after the milk extraction, concentration of coconut water by membrane processing, preservation of coconut water by emerging technologies will also be discussed.
\end{abstract}

\section{Introduction}

The word 'Coco' is derived from Spanish word 'Macoco', which refers to three holes on coconut that resemble the face of an ape. The coconut is mainly produced in southern states of India such as Kerla, Karnataka, Andhra Pradesh, Maharashtra etc. The tree of coconut is called as kalptaru, because all the parts of it are useful in one form or the other. Specially, the kernel of matured coconut is most valuable and is used for edible purpose as such or in dehydrated form. The dried kernel known as 'copra' and is the richest source of vegetable oil and the coconut oil cake is a valuable feed for livestock and a source of protein. The coconut shell is mainly used as a fuel, for making decorative items, shell powder, shell charcoal and biodegradable containers etc. The husk yields fiber, which is converted into coir and its products. The coir pith obtained during the defibring process is used as an ideal soil conditioner. The coconut water is one of the valuable by-products of the coconut processing industries, which can be subjected to fermentation to produce vinegar. The economy of the coconut-processing sector is mainly dependent on the copra and coconut oil, and on desiccated coconut to a less extent. About $60 \%$ of the total coconut production is used for edible purpose, 3.5\% as tender coconut, 35\% as milling copra for oil extraction and balance is processed into products like desiccated coconut. Coconut oil contributes about $6 \%$ of the total edible oil demand.

In order to develop the diversified products from coconut and to improve the economy of this sector Coconut Development Board, India has taken a welcome step in sponsoring research projects at different institutions for the development of technologies in this regard. CSIR-CFTRI is in forefront in developing technologies pertaining to diversified products from coconut.

\section{Coconut Related Technologies Developed at CFTRI}

\section{A. Desiccated Coconut Powder}

The process includes removal of shell and paring, disintegration of white endosperm, final drying in the drier and then packaging. On an average 1000 nuts give $110 \mathrm{~kg}$ of DCP. 
Several units located in India produce about 15,000 tons annually. All are in the small-scale sector with capacities ranging from 0.5-1.0 ton per day. DCP is mainly used in biscuits, sweets, bakery products and other food preparations.

\section{B. Spray Dried Coconut Milk Powder}

Coconut milk is a product of the region of tropical climate and is in great demand in the international culinary. It is a white milky product extracted from the endosperm of coconut and constitutes into an emulsion stabilized by proteins and probably, by some ions found in oil-water interface. Coconut milk is an important dietary in coconut producing countries. It is valued mainly for its characteristic nutty flavour and also for its nutritional values. It is an ingredient for many fish, shellfish, meat, poultry, vegetable dishes, confectioneries, sweets, serbhats, beverages and other type of preparations. Under ambient conditions coconut milk shows poor stability and the emulsion separates into two distinct phases: a heavy aqueous phase and a lighter creamy phase. Coconut milk extracted from freshly grated coconut meat undergoes very fast progressive deterioration at room temperature due to its high content of fat, moisture and other organic components, which quickly deteriorate upon exposure to microorganism, light, oxygen and high temperature.

Based on our previous experience and published reports, it was opined that dehydration is the best feasible method for the preservation of coconut milk. Dehydrated coconut milk powder which retains the natural flavour and texture of coconut milk, yet has good keeping quality, would lead to greater convenience and increased consumption. Individual and institutional user would be relieved from the task of extracting milk. Further, it offers additional advantages such as less storage space and extended shelf life. Very little information is available in the literature regarding the dehydration of whole coconut milk, though lot of information is available on dehydration of skim coconut milk powder. And out of available information most of it either remained proprietary or available in languages other than English or in the form of patents. The only report available is work of Hassan [1].

The process for the production of whole coconut milk powder involves various unit operations such as size reduction, extraction of milk, stabilization of emulsion, homogenization and spray drying. The coconut milk contains large amount of fat, which poses difficulty in achieving its stabilization during spray drying. A process was developed to stabilize coconut milk, which enables spray drying [2]. Recently, technology for the production of whole coconut milk powder has been transferred to an Indian industry. The process was developed for detachment of coconut kernel from shell [3]. The white endosperm after removal of shell and paring was passed through rotary wedge cutter having a sieve plate ( $3 \mathrm{~mm}$. hole) through which shredded meat is forced out. This moist coconut grating was expressed in a screw press to extract coconut milk. Coconut milk, thus obtained, was homogenised in two stage of high and low pressures, respectively, over a period of 30 minutes. Then coconut milk was formulated by addition of certain ingredients and chemicals etc. This formulated coconut milk was pasteurised at $60-70^{\circ} \mathrm{C}$ for 5 minutes and homogenised again. Finally, the milk was spray dried at temperature $100-150^{\circ} \mathrm{C}$ at a feed flow rate of $120 \mathrm{ml} /$ minute and packed [4]. The flow sheet of the process is given in Figure 1.

Apart from the processing technology, quality and yield of the extract (coconut milk) is affected by several factors such as varietal differences, coconut maturity, meat particle size, processing temperature and extraction pressure. It is observed that maturity of coconut has considerable effect on the yield of coconut milk. It was observed that the yield was less if the coconuts were over or under matured. When the meat particle size was less it was observed that 
yield of coconut milk was higher because of the effective rupture of cells. Increased pressure in the screw press resulted in increased yield of milk.

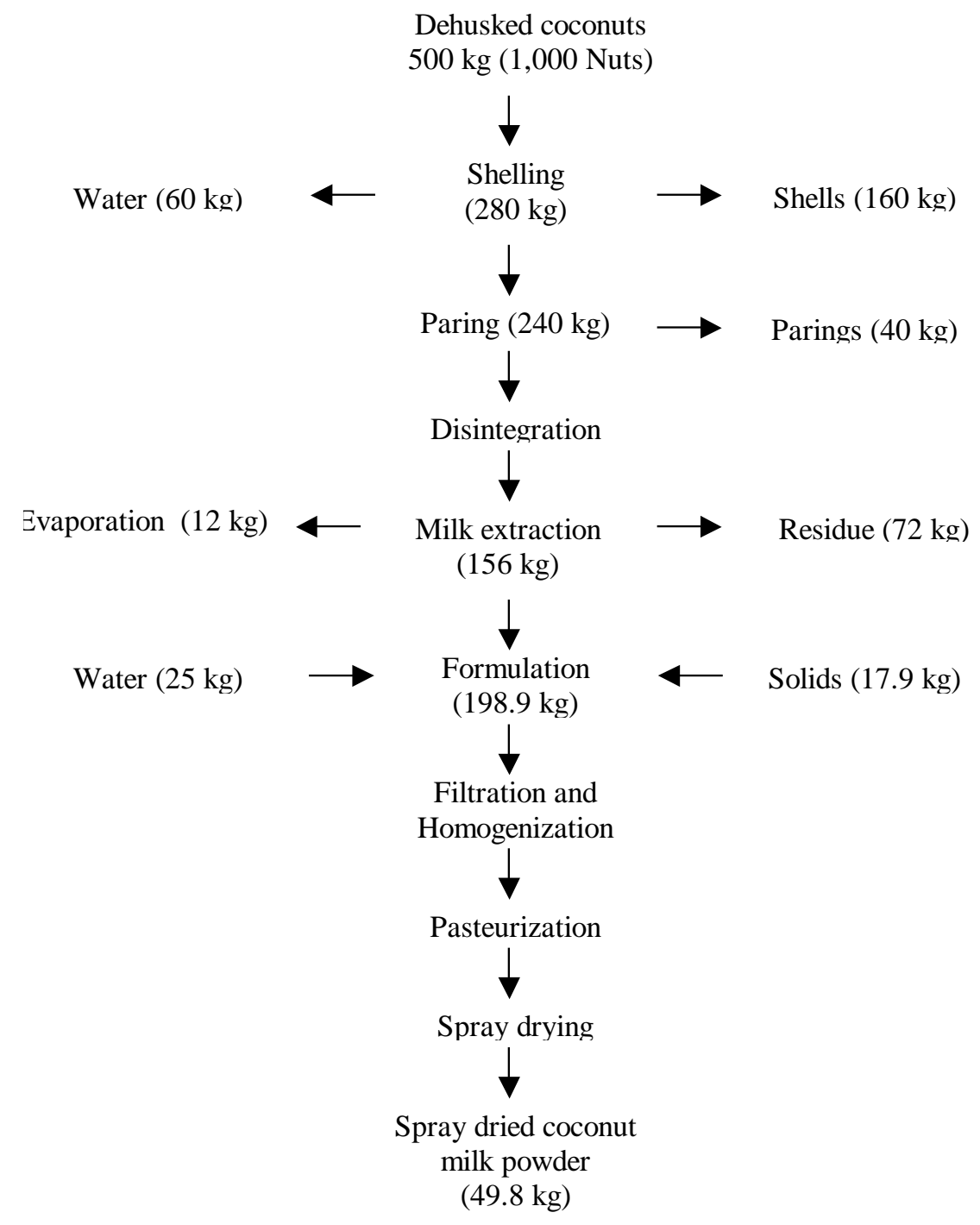

Fig. 1: Flow sheet for the production of spray dried coconut milk powder.

\section{Virgin Coconut Oil by Wet Processing}

The white endosperm portion of coconut is disintegrated and squeezed in screw press to recover coconut milk, which is filtered, and cream is separated by centrifugation. The cream is stirred vigorously to get the virgin coconut oil (VCO) by a process called phase inversion. The oil thus obtained is very clear, nutritious and has a longer shelf life. The residual coconut cake can be dried and sold as medium/low fat desiccated coconut, which may find application in bakery and formulation of low calorie foods. The skim milk obtained from centrifugation can be concentrated and spray dried. The value-added by-products render the whole process quite economical one. Virgin coconut oil (VCO) is prepared from fresh mature coconuts by wet processing without any heat treatment [5]. VCO is colourless and having an intense coconut aroma. It is rich in lauric fatty acid, which is a proven antiviral and anti-bacterial agent. The high-grade VCO has a long shelf life due to presence of natural anti-oxidents in coconut oil. Coconut milk is extracted from deshelled, pared and disintegrated coconuts. Further, coconut 
cream is separated, which is subjected to tempering, conditioning and separation techniques to separate VCO. Material balance for VCO production is presented in Figure 2. Coconut oil is a product of the region of tropical climate and is in great demand in the cosmetic industry and international culinary. It is valued mainly for its characteristic nutty flavour and also for its nutritional values. The novelty of our invention lies in the manner in which the VCO is obtained without heat treatment of coconut milk or fermentation of coconut cream, thereby keeping its characteristic flavour and nutrients intact.

Ultrafiltration in combination with spray drying was also explored as a method for the production of coconut whey protein powder. The coconut whey was centrifuged to remove fat and then it was subjected to ultrafiltration using membranes of MWCO of 5, 10, 30 and $50 \mathrm{kDa}$. The retentate and permeate were collected. It was found that MWCO of $5 \mathrm{kDa}$ gave maximum retention of proteins in the retentate (96\%). The ultrafiltration was performed in the pressure range of 2 to 10 bar. The separation process occurring across a membrane discriminates solute molecules on the basis of their sizes. The retentate collected was then spray dried to get coconut protein powder.

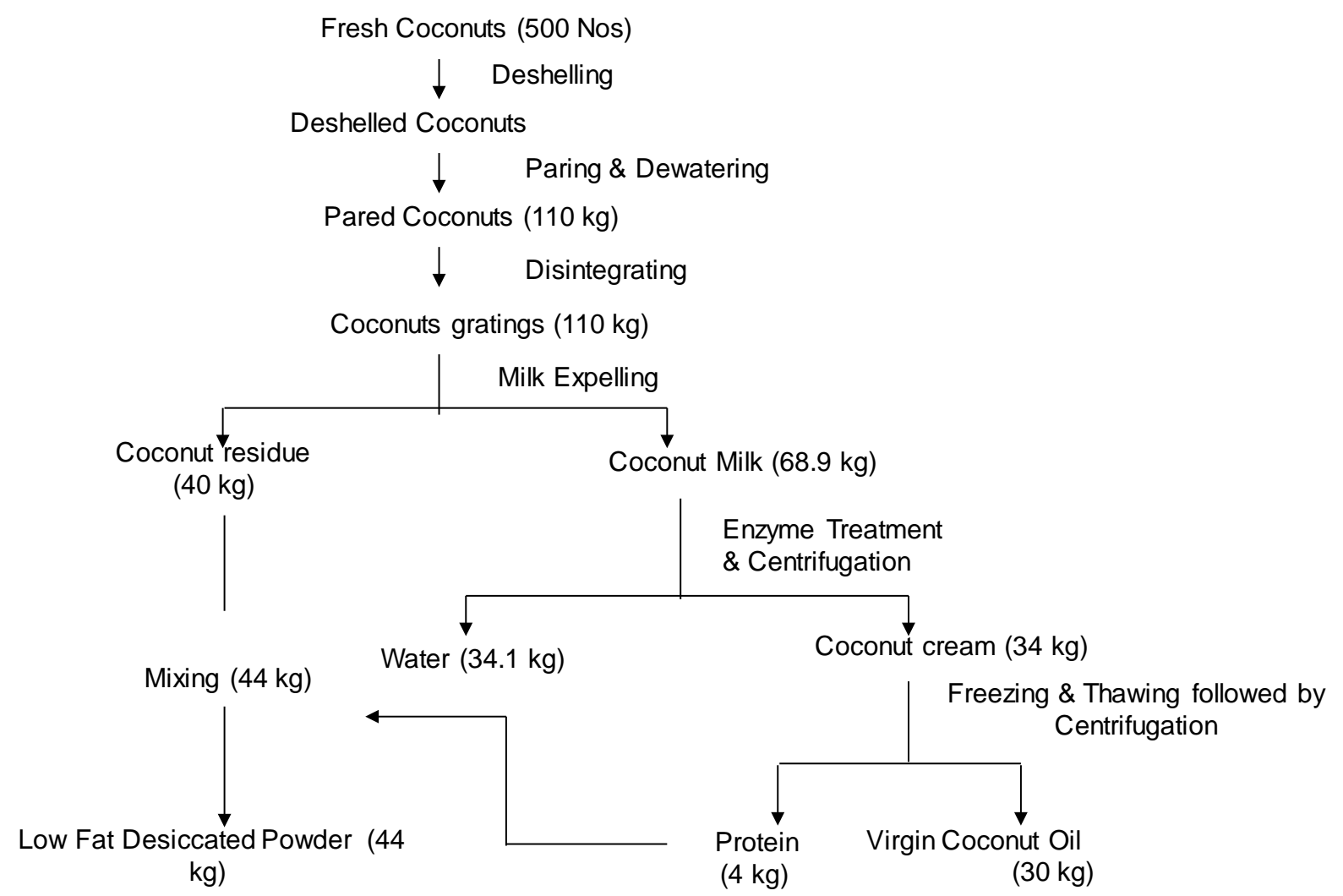

Fig. 2: Material balance for VCO production.

\section{Mature Coconut Water}

Coconut water (yield 28\%) is a very important by-product from coconut processing industries, because it contains about 2.5-3.0\% sugar, which can be utilised as a fermentation substrate for the production of vinegar. Vinegar is the product of two stage fermentation process. In the first stage, sugars are converted into ethyl alcohol by the action of yeast (Saccharomyces cerevisiae) in a anaerobic fermentation process. In the second stage of fermentation process, bacteria (Acetobector) oxides ethyl alcohol to acetic acid [6]. It is an aerobic fermentation of exothermic 
nature. During the fermentation process series of reaction takes place. Since minimum requirement of total fermentable sugars in the substrate should be in the range 8-10\%, it is supplemented from the external source. The cost of sugar (or jaggery) may be compensated with the recovery of value added by-products, besides solving the pollution problems and amount incurred in its disposal.

The vinegar generator is designed to provide the maximum surface exposure for a volume of fermented coconut water in order to supply enough air for the acetic bacteria to efficiently and quickly oxidises the alcohol to acetic acid. The generator assembly usually comprises a feed trough, and acetifier and receiving trough. In essence, it is counter current gas absorber wherein the acetic bacteria causes the oxidation of ethyl alcohol to acetic acid. The feed is uniformly sprayed over the surface of an inert porous packing medium (corn cobs) at the surface of which the oxidation takes place. The stock which drains off from the packing by gravity into the base of the generator is run out and pumped back into the feed vat from which it is recycled until acetification is complete. When the vinegar is reached its maximum strength $(4.0 \%)$, it is aged before bottling. In certain coconut growing countries like Philippines, coconut water is used to produce a sweet dessert dish called Nata-de-coco which is also popular as a component of fruit salad, ice-creams, fruit salads and fruit cocktails.

The use of coconut water adds favorably to the economics of the existing coconut industries. Mature coconut water procured from desiccated coconut industry and was filtered and centrifuged to remove suspended solids and fats. Mature coconut water was passed through cationic, anionic and mixed bed resins to remove saltiness caused by the minerals in the final product. The mature coconut water was then subjected to thin film evaporator to achieve $47^{\circ} \mathrm{B}$. Further, coconut spread was prepared by partial replacement of sugar with concentrate from mature coconut water along with addition of other ingredients such as citric acid, pectin and benzoic acid followed by thermal treatment. Addition of coconut dietary fiber, which can be evenly suspended in the spread, provides a characteristic coconut flavor, texture and taste. Partial or optimized level of replacement of sugar (50\%) with mature coconut water concentrate yielded a very highly acceptable product having characteristic taste and flavor [7].

\section{E. Dietary Fiber}

Dietary fiber refers to the plant substances including plant cell wall (cellulose, hemi cellulose, pectin and lignin) as well as intracellular polysaccharides such as gums and mucilage that are not digested by human digestive enzymes [8]. The main components of dietary fiber are cellulose, hemi cellulose, starch, pectin substance (polygalacturonic acid components) and lignin [9]. Amongst these, only cellulose and a portion of retrograded starch (called resistance starch) are insoluble in water, while the other are soluble. The non-starch polysaccharides act as bulking agent or roughage in the food. Dietary fiber is considered as a physiologically inert material although the bulking and laxative properties of many fiber sources have long been appreciated [10]. It has been shown to play an important role in the prevention of the risk of carcinogenesis, atheroscler-osis and in the control and proper management of diabetes mellitus [11]. During the wet processing of coconut, fresh coconuts, after shelling and paring, were disintegrated and expressed to extract coconut milk, which was either used for the preparation of virgin coconut oil or spray dried coconut milk powder. The grinding of coconut residue after the fat extraction led to the rupture of the honey comb physical structure (matrix) resulting in a flat ribbon type structure, thereby providing an increase in surface area for water and fat absorption, which can be utilized as dietary fiber $[12,13]$. The grinding has to be done in such a way that the resultant product size must be $\sim 550$ micrometer. During solvent extraction the fat content of the product 
should be reduced to less than $2 \%$ and product has to be dried completely. The presence of higher content of fat and moisture resulted in inadequate grinding, which led to the reduction in water as well as fat absorption properties. A very fine or very coarse product will lead to decrease in water as well as fat absorption properties. Hydration properties of coconut dietary fiber were compared with other commercially available dietary fibers Figure 3. Except for apple fiber $(5.43 \mathrm{~g} / \mathrm{g})$ and citrus fiber $(10.66 \mathrm{~g} / \mathrm{g})$, the water retention capacity of coconut dietary fiber $(5.4 \mathrm{~g} / \mathrm{g})$ was higher compare to all other the samples. Water holding capacity of coconut fiber $(7.1 \mathrm{~g} / \mathrm{g})$ was also more than that of the other samples. Coconut fiber showed highest swelling capacity $(20 \mathrm{ml} / \mathrm{g})$ as compared to any other fiber studied. This showed that coconut fiber has the maximum capacity to swell when compared to other fibers, which is the most desirable parameter for physical functioning of dietary fiber $[12,13]$.

\section{F. Tender Coconut Water}

Coconut beverage was produced from the solid (white meat) as well as liquid (coconut water) endosperm from tender coconut having good shelf life, sensory properties and characteristics coconut flavour. It is of white color and viscous in nature. The tender coconut beverage can be packaged, distributed and sold commercially due to the presence of natural electrolytes, refreshing and fresh taste of coconut. The tender coconut water and thin solid endosperm from the tender coconut and was homogenized in the ratio 4:1, the homogenized mixture was formulated with sugar and xanthan. The formulated beverage was filtered with cheesecloth, heated up to $90^{\circ} \mathrm{C}$ and filled in pre-sterilized glass bottles. The bottles were subjected to hot water to expel the air present in the headspace. Further, the bottles were sealed and autoclaved. Figure 4 represents the flowchart for the production of tender coconut beverage

The product was found to have characteristic taste and aroma of tender coconut and no preservative was used in this process. The novelty of the present invention lies in the way of selecting the processing steps, conditions/ parameters and components to obtain a value added product, which is not hitherto available, without losing the characteristic flavour of tender coconut.

Tender coconut water concentrate is a rich source of proteins and micro-nutrients, besides, preserving the flavor, color and nutrition. The process includes initial concentration of coconut water by reverse osmosis and further concentration was achieved by osmotic membrane distillation [14]. This novel approach involves no heat treatment, thus retaining the flavors of tender coconut largely.

\section{Conclusion}

Other technologies available are canned coconut chunk in brine, canning of coconut cream and process for canning of tender coconut water, coconut beverage from tender coconut and coconut spread. Of course, the coconut research may take vibrant trend with the advent of latest technologies such as membrane processing and other techniques. These things are only possible when regulatory and governing agencies come forward to sponsor further research projects in this potential field. It would be very encouraging if the food industries come closer to R\&D institutions and work together for development of state-of-the-art technologies and can finance part of the research.

\section{Acknowledgement}

The author wishes to gratefully acknowledge the constant encouragement of Dr. KSMS Raghavarao, Director, CFTRI. This work was carried out under the project funded by Coconut Development Board (CDB), Kochi, India. 


\section{References}

[1] M.A. Hassan, Spray drying of coconut milk Pertanika, 8 (1985) 127-130.

[2] N.K. Rastogi et al., A process for the preparation of stable whole coconut milk, Indian Patent number 184681 (1995).

[3] N.K. Rastogi, K.S.M.S. Raghavarao, S.G. Jayaprakashan, A process for detachment of coconut kernel from its shell. Indian Patent Appl. 2638/DEL/96 (1996).

[4] N.K. Rastogi, K.S.M.S. Raghavarao, Production of dehydrated coconut milk powder, In the National Seminar on Processing and Marketing of Coconut (SPAMCO II), Bangalore (1992).

[5] N.K. Rastogi et al., A process for the production of virgin coconut oil, Indian Patent Appl. number 443/DEL/2009 (2009).

[6] C.T. Dwarakanath, Vinegar Fermentation with Special Emphasis on Possibilities of Coconut water, In the National Seminar on Processing and Marketing of Coconut (SPAMCO II), Bangalore (1992).

[7] N.K. Rastogi, K.S.M.S Raghavarao, M. Prakash, A process for the production of coconut spread based on mature coconut- water concentrate and coconut dietary fiber, Indian Patent Application number 0287/DEL/2009 (2009).

[8] G.A. Spiller, CRC Hand book of: Dietary fiber in human nutrition. CRC Press, New York, 2000, pp. 9-10.

[9] M.S. Wolthuis, H.F.F. Albers, J.G.C. Jeveren, J.W. Jong, J.G.A.J. Hautvast, R.J.J Hermus, M.B. Katan, W.G. Brydon, M.A. Eastwood, The American Journal of Clinical Nutrition 33 (1980) 1745-1756. https://doi.org/10.1093/ajcn/33.8.1745

[10] K.L. Roehrig, Food Hydrocolloids 2 (1988) 1-18.

[11] T.P. Trinidad, D. Valdez, A.C. Mallillin, F.C. Askali, A.S. Maglaya, M.T. Chua, J.C. Castillo, A.S. Loyola, D.B. Masa, Indian Coconut Journal 7 (2001) 45-50.

https://doi.org/10.1016/j.ifset.2004.04.003

[12] S.N. Raghavendra, N.K. Rastogi, K.S.M.S. Raghavarao, R.N. Tharanathan, Dietary fiber from coconut residue: effect of different treatments and particle size on the hydration properties, European Food Research and Technology 218-6 (2004) 563-567.

https://doi.org/10.1007/s00217-004-0889-2

[13] S.N. Raghavendra, S.R. Ramchandra Swamy, N.K. Rastogi, K.S.M.S Raghavarao, Sourav Kumar, R.N. Tharanathan, Grinding characteristics and hydration properties of dietary fiber from coconut residue, Journal of Food Engineering 72 (2006) 281-286.

https://doi.org/10.1016/j.jfoodeng.2004.12.008

[14] S.N. Raghavendra, N.K. Rastogi, K.S.M.S. Raghavarao, M. Prakash, A process for the preparation of tender coconut beverage, Indian Patent Application number 283/DEL/2009 (2009). 